
ISSN : 2615-1995, E-ISSN : 2615-0654

J. Madani., Vol. 2, No. 1, Maret 2019 (163 - 173)

(C)2018 Lembaga Kajian Demokrasi

MADANI

dan Pemberdayaan Masyarakat (LKD-PM)

\title{
PENGARUH INTEREST INCOME GROWTH, NET WORKING CAPITAL, DAN CAPITAL EXPENDITURE TERHADAP CASH HOLDING DENGAN AKTIVITAS DEWAN KOMISARIS SEBAGAI VARIABEL MODERASI
}

\author{
Sjamsul Maarif \\ Fakultas Ekonomi dan Bisnis, Universitas Pancasila \\ sjamsul.m@gmail.com \\ Choirul Anwar \\ Fakultas Ekonomi dan Bisnis, Universitas Pancasila \\ Darmansyah \\ Fakultas Ekonomi dan Bisnis, Universitas Pancasila
}

\begin{abstract}
Abstrak
Penelitian ini bertujuan untuk menguji pengaruh Interest Income Growth (IIG), Net Working Capital (NWC) dan Capital Expenditure (CAPEX) terhadap Cash Holding (CH). pada perusahaan Jasa Keuangan yang terdaftar di Bursa Efek Indonesia periode 2012-2016. Penelitian ini juga menguji peran Aktivitas Dewan Komisaris sebagai variabel moderasi dalam hubungan antara Interest Income Growth, Net Working Capital dan Capital Expenditure perusahaan. Populasi dalam penelitian ini adalah 64 perusahaan jasa keuangan di Bursa Efek Indonesia. Sampel didapatkan dengan metode purposive sampling. Hipotesis dalam penelitian ini diuji dengan regresi linier berganda dan Structural Equaton Modeling (SEM) dengan program WarpPLS 6.00. Hasil penelitian ini menunjukkan bahwa: Interert Income Growth (IIG) berpengaruh positif signifikan terhadap Cash Holding; Net Working Capital (NWC) terhadap Cash Holding tidak berpengaruh; Capital Expenditure terhadap Cash Holding tidak berpengaruh signifikan; hubungan antara Interest Income Growth terhadap Cash Holding yang dimoderasi oleh ADK berpengaruh signifikan; hubungan antara Net Working Capital (NWC) terhadap Cash Holding yang dimoderasi oleh ADK tidak signifikan; hubungan antara Capital Expenditure (CAPEX) terhadap Cash Holding yang dimoderasi oleh ADK berpengaruh signifikan.
\end{abstract}

Kata Kunci : Interest Income Growth, Net Working Capital,Capital Expenditure, Aktivitas Dewan Komisaris, Cash Holding

\begin{abstract}
This study aims to examine the effect of Interest Income Growth (IIG), Net Working Capital (NWC) and Capital Expenditure (CAPEX) on Cash Holding (CH). Financial Services companies listed on the Indonesia Stock Exchange for the period 2012-2016. This study also examined the role of Board of Commissioners' Activity as a moderating variable in the relationship between Interest Income Growth, Net Working Capital and Capital Expenditure of the company. The population in this study were 64 financial service companies on the Indonesia Stock Exchange. Samples were obtained by purposive sampling method. The hypothesis in this study was tested by multiple linear regression and Structural Equaton Modeling (SEM) with the WarpPLS 6.00 program. The results of this study indicate that: Interest Income Growth (IIG) has a significant positive effect on Cash Holding; Net Working Capital (NWC) against Cash Holding has no effect; Capital Expenditure on Cash Holding has no significant effect; the relationship between Interest Income Growth to Cash Holding moderated by ADK has a significant effect; the relationship between Net Working Capital (NWC) to Cash Holding moderated by ADK is not significant; the relationship between Capital Expenditure (CAPEX) to Cash Holding moderated by ADK has a significant effect.
\end{abstract}

Keywords : Net Working Capital,Capital Expenditure, Board of Commissioners Activities, Cash Holding 


\section{PENDAHULUAN}

\section{Latar Belakang}

Akuntansi adalah suatu seni atau kecakapan dalam mencatat, mengklasifikasikan, menggolongkan, mengikhtisiarkan dengan suatu metode tertentu (secara standard) dalam satuan uang atas semua transaksi yang bersifat keuangan. Akuntansi merupakan informasi keuangan yang dibutuhkan oleh pihak luar (eksternal) dan pihak dalam (internal) perusahaan. (Harmono (2015).

Kas merupakan aktiva yang sangat likuid dan dapat digunakan dengan segera untuk memenuhi kebutuhan dari aktivitas perusahaan. Persediaan kas ditangan (cash holdings) merupakan uang tunai yang termasuk dalam kategori aktiva lancar. Cash holdings yang optimal merupakan kas yang harus dijaga oleh perusahaan agar tidak mengalami kelebihan atau kekurangan, dan harus disediakan dalam batas jumlah yang telah ditentukan. Perusahaan dengan tingkat cash holding rendah tidak mampu bertahan lama disaat krisis karena mereka tidak bisa beroperasi lagi akibat tidak memiliki cukup dana untuk membeli bahan baku yang semakin mahal. (Bateset al.2009) dalam Husnan (2013)

Penelitian cash holdings sudah menjadi hal yang menarik untuk diteliti, sehingga banyak penelitian-penelitian yang sudah dilakukan dengan hasil yang berbeda. Penelitian yang dilakukan William \& Fauzi (2013), Marfuah \& Zulhilmi (2015), Gill \& Shah (2012) dan Jinkar (2013), menemukan adanya pengaruh net working capital terhadap cash holdings.

Ur Rehman dan Wang (2015), dalam penelitiannya menemukan bahwa working capital, capital expenditure aktivitas dewan komisaris berpengaruh signifikan terhadap cash holdings. Warsono (2016) menemukan bahwa capital expenditure berpengaruh terhadap cash holding; sementara itu Rahmawati (2013), menemukan bahwa dan net working capital tidak berpengaruh terhadap cash holdings. Bigelli dan Vidal (2009), yang menyatakan bahwa Terdapat hubungan positif dan signifikan antara variabel growth opportunity dengan cash holding.

Berdasarkan uraian diatas, perbedaan hasil penelitian yang terjadi diatas, maka peneliti akan menguji kembali apakah adanya pengaruh net working capital, Capital Expendituredan, Interest income growth terhadap cash holdings dengan aktivitas Dewan Komisaris sebagai variabel moderasi pada perusahaan sektor jasa keuangan yang terdaftar di Bursa Efek Indonesia periode 2012-2016.

\section{Pembatasan Masalah}

Berdasarkan identifikasi masalah dan pertimbangan waktu dan tenaga serta supaya pe- nelitian dapat dilakukan lebih fokus maka tidak semua masalah akan di teliti. Oleh karena itu, penelitian ini dibatasi oleh hal-hal berikut :

a. Sampel yang akan diteliti adalah perusahaan dalam kelompok jasa keuangan yang terdaftar di Bursa Efek Indonesia (BEI), aktif melakukan transaksi serta menerbitkan laporan keuangan tahunan dalam periode penelitian.

b. Variabel independent yang di teliti adalah Interest Income Growth, Net Working Capital, dan Capital Expenditure.

c. Aktivitas Dewan Komisaris dipilih sebagai variabel Moderasi terhadap Cash Holding.

\section{Kajian Pustaka}

\section{Trade Off Theory}

Menurut Husnan (2015) trade off theory menyatakan bahwa cash holdings perusahaan dikelola dengan mempertimbangkan batasan antara biaya dan manfaat (cost and benefit) yang didapatkan dalam menahan kas. Keputusan yang tepat dalam mengelola kepemilikan kas akan konsisten dengan tujuan perusahaan yaitu memaksimalkan nilai perusahaan.

Menurut Harjito dan Martono dalam Syafrizaliadhi (2014) cash holdings atau kepemilikan kas dapat digunakan untuk transaksi seperti untuk pembayaran gaji atau upah, pembelian aktiva tetap, membayar utang, membayar dividend dan transaksi lain yang diperlukan perusahaan.

\section{Pecking Order Theory}

Menurut Fahmi (2012), pecking order theory merupakan suatu kebijakan yang ditempuh oleh suatu perusahaan untuk mencari tambahan dana dengan cara menjual aset yang dimilikinya. Seperti menjual gedung, tanah, peralatan yang dimilikinya dan aset-aset lainnya, termasuk dengan menerbitkan dan menjual saham dipasar modal dan dana yang berasal dari laba ditahan.

\section{Agency Theory}

Menurut Harmono (2015), agency cost merupakan berkurangnya kekayaan pemilik yang ditimbulkan dari alokasi sumber daya yang tidak efisien yang disebabkan oleh konflik kepentingan antara pemegang saham, kreditor, dan para manajer.

\section{Cash Holding}

Cash adalah salah satu bagian dari banyak aset yang dewasa ini paling liquid dan paling mudah berpindah tangan dalam transaksi. Cash holdings atau kepemilikan kas dapat digunakan untuk transaksi seperti untuk pembayaran gaji atau upah, pembelian aktiva tetap, membayar utang, membayar dividend dan transaksi lain yang diperlukan perusahaan. Cash adalah se- 
buah aset yang tidak dapat menghasilkan sebuah "keuntungan", maksudnya tidak sanggup untuk keuntungan langsung dalam operasional perusahaan. Oleh karena itu, upaya-upaya perlu pemanfaatan manajemen cash yang efektif dan efisiensi cash yang optimal (Harjito dan Martono, 2005 dalam Abdullah 2015).

Menurut Gill and Shah (2012), cash holdings didefinisikan sebagai kas yang ada di perusahaan atau tersedia untuk investasi pada aset fisik dan untuk dibagikan kepada investor.

Cash holdings dipandang sebagai kas dan ekuivalen kas yang dapat dengan mudah diubah menjadi uang tunai. Kaitannya dengan perusahaan, cash holdings memiliki arti penting bagi perusahaan. Penentuan tingkat cash holdings merupakan keputusan penting yang harus diambil oleh manajer keuangan.

Menurut Ekawati (2014 kas merupakan akttiva yang sangat likuid dan dapat digunakan dengan segera untuk memenuhi kbutuhen dari aktivitas perusahaan. Persediaan kas di tangan (Cash holding) merupakan uang tunai yang termasuk dalam kategori aktiva lancar. Cash holding yang optimal merupakan kas yang harus dijaga oleh perusahaan agar tidak terjadi kelebihan atau kekurangan, dan harus disediakan dalam jumlah yang telah ditentukan. Penentuan cash holding yang optimal perlu dilakukan karena kas merupakan elemen modal kerja yang paling diperlkan untuk memenuhi kegiatan operasional perusahaan sehari-hari.

\section{Kerangka Pemikiran}

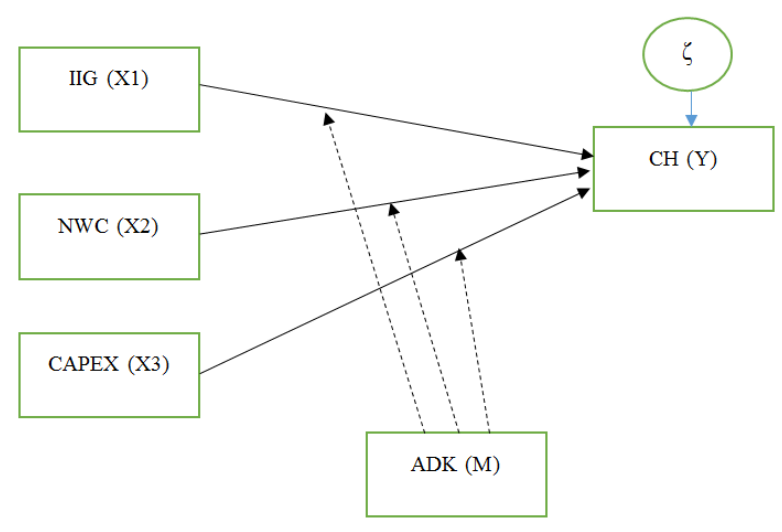

Gambar 2.2. Kerangka Pemikiran

Keterangan :

$\begin{array}{ll}\text { IIG } & : \text { Interset Income Growth } \\ \text { NWC } & : \text { Net Working Capital } \\ \text { CAPEX } & : \text { Capital Expenditure } \\ \text { ADK/MEET } & : \text { Aktivitas Dewan Komisaris } \\ \text { CH } & : \text { Cash Holding }\end{array}$

\section{Pengembangan Hipotesis}

Meningkatnya interest income growth membutuhkan cadangan modal dalam jumlah yang besar juga untuk memenuhinya. Di samping itu, meningkatnya interest income growth juga didukung oleh meningkatnya jumlah kredit yang dimiliki perusahaan. Seiring dengan meningkatnya interest income growth, peluang berinvestasi pada operasi perusahaan yang berbeda ikut meningkat (Anjum dan Malik,2013). Islam (2012) menunjukkan hasil positif atas peluang berinvestasi, yang didukung dengan teori trade off yang memiliki pendapat bahwa adanya pengauh positif pertumbuhan penjualan terhadap cash holding. Dalam peningkatan pemenuhan investasi atau pemberian kredit terhadap nasabah diperlukan kecukupan modal dalam bentuk kas dan perushaan akan memperoleh pendapatan atas kredit yang disalurkan (warsono, 2016).

\section{$\mathrm{H}_{1}=$ Interest Income Growth mempunyai pengaruh positif terhadap cash holdings}

Teori trade off menyimpulkan adanya hubungan negatif antara net working capital terhadap cash holdings. Menurut Ogundipe et al. (2012), net working capital dipakai sebagai proksi dari investasi pada aset lancar yang dapat dipakai sebagai pengganti kas. Ketika dibutuhkan, net working capital dapat dilikuidasi dengan cepat untuk menutupi kekurangan kas yang dibutuhkan perusahaan (Islam, 2012).

\section{$\mathrm{H}_{2}=$ Net working capital mempunyai penga- ruh negatif terhadap cash holdings}

Capital expenditure diukur dengan menggunakan capital expenditure dibagi dengan total aset. Ketika suatu perusahaan memiliki rencana untuk melakukan investasi besar, maka perusahaan akan membuat cadangan kas untuk menjaga kelangsungan pengerjaannya. Dengan keberadaan cadangan kas maka cash holding perusahaannya akan tinggi. Secara emipiris telah dibuktikan oleh penelitian Kusnadi (2003) dalam rahmawati (2014). Berdasarkan argumen tersebut, penelitian ini didasari pada keyakinan bahwa ada hubungan positif antara capital expenditure dengan kebijakan cash holding perusahaan sesuai dengan Trade Off (Jinkar, 2013).

Trade off teori mengharapkan hubungan positif karena perusahaan yang memiliki capital expenditure yang tinggi akan menahan kas sebagai perlindungan terhadap biaya transaksi terkait dengan modal eksternal dan biaya kesempatan pada sumber daya yang kurang memadai (Daher dalam Syafrizalliadhi,2014).

\section{$\mathrm{H}_{3}=$ Capital expenditure mempunyai penga- ruh positif terhadap cash holdings}

Dewan komisaris merupakan suatu mekanisme corporate governance berupa media dalam mengawasi dan memberikan petunjuk serta arahan pada manajemen. Dalam implementasinya 
aktivitas dewan komisaris memegang peranan yang sangat penting dalam perusahaan, terutama dalam pelaksanaan mekanisme penerapan GCG dalam bentuk pertemuan rapat yang diadakan oleh dewan komisaris berfungsi sebagai media komunikasi formal anggota dewan komisaris dalam mengawasi proses corporate governance, memastikan bahwa manajemen membudayakan corporate governance, memonitor bahwa perusahaan tunduk pada code of conduct, mengerti semua pokok persoalan yang mungkin dapat mempengaruhi kinerja finansial atau non-finansial perusahaan, memonitor bahwa perusahaan tunduk pada tiap undang-undang dan peraturan yang berlaku, dan mengharuskan auditor internal melaporkan secara tertulis hasil pemeriksaan corporate governance dan temuan lainnya.

Dengan melakukan rapat secara periodik, dewan komisaris dapat mencegah dan mengurangi kemungkinan terjadinya kondisi kesulitan keuangan karena aktivitas pengendalian internal perusahaan dilakukan secara terus menerus dan terstruktur sehinga setiap permasalahan dapat cepat terdeteksi dan diselesaikan dengan baik oleh manajemen. Semakin tinggi intensitas rapat dewan komisaris, maka akan semakin meningkatkan monitoring atau evaluasi terhadap kinerja perusahaan sehingga akan bermanfaat pada semakin meningkatnya tingkat likuiditas perusahaan dan akan tersedianya kas dan setara dengan kas.

Meningkatnya interest income growth membutuhkan cadangan modal dalam jumlah yang besar juga untuk memenuhinya. Di samping itu, meningkatnya interest income growth juga didukung oleh meningkatnya jumlah kredit yang dimiliki perusahaan. Seiring dengan meningkatnya interest income growth, peluang berinvestasi pada operasi perusahaan yang berbeda ikut meningkat (Anjum dan Malik, 2013). Islam (2012) menunjukkan hasil positif atas peluang berinvestasi, yang didukung dengan teori Trade off yang memiliki pendapat bahwa adanya pengaruh positif pertumbuhan penjualan terhadap Cash Holding. Dalam peningkatan pemenuhan investasi atau pemberian kredit terhadap nasabah diperlukan kecukupan modal dalam bentuk kas dan perushaan akan memperoleh pendapatan atas kredit yang disalurkan (warsono, 2016).

\section{H.1.a = Aktivitas Dewan komisaris dapat me- moderasi Interest Income Growth ter- hadap Cash Holding}

Dewan komisaris merupakan suatu mekanisme corporate governance berupa media dalam mengawasi dan memberikan petunjuk serta arahan pada manajemen. Dalam implemen- tasinya dewan komisaris memegang peranan yang sangat penting dalam perusahaan, terutama dalam pelaksanaan mekanisme penerapan GCG.

Teori Trade off menyimpulkan adanya hubungan negatif antara net working capital terhadap Cash Holding. Menurut Ogundipe et al. (2012), net working capital dipakai sebagai proksi dari investasi pada aset lancar yang dapat dipakai sebagai pengganti kas. Ketika dibutuhkan, net working capital dapat dilikuidasi dengan cepat untuk menutupi kekurangan kas yang dibutuhkan perusahaan (Islam, 2012).

\section{H.2.a = Aktivitas Dewan Komisaris tidak da- pat memoderasi Net Working Capital terhadap Cash Holding}

Proses rapat dewan komisaris baik rapat internal anggota mapun eksternal dengan pihak direksi maupun pihak lainnya (board process) merupakan hal yang penting dan berpengaruh dalam menentukan efektifitas dewan komisaris dan ketika suatu perusahaan memiliki rencana untuk melakukan investasi besar, maka perusahaan akan membuat cadangan kas untuk menjaga kelangsungan pengerjaannya. Dengan keberadaan cadangan kas maka Cash Holding perusahaannya akan tinggi. Secara emipiris telah dibuktikan oleh penelitian Kusnadi (2003) dalam rahmawati (2014). Berdasarkan argumen tersebut, penelitian ini didasari pada keyakinan bahwa ada hubungan positif antara $c a-$ pital expenditure dengan kebijakan Cash Holding perusahaan sesuai dengan Trade off (Jinkar,2013).

Trade off teori mengharapkan hubungan positif karena perusahaan yang memiliki capital expenditure yang tinggi akan menahan kas sebagai perlindungan terhadap biaya transaksi terkait dengan modal eksternal dan biaya kesempatan pada sumber daya yang kurang memadai (Daher dalam Syafrizalliadhi,2014).

\section{H.3.a = Aktivitas Dewan Komisaris dapat me- moderasi Capital Expenditure terhadap Cash Holding}

\section{METODE}

\section{Operasionalisasi Variable Penelitian Variable Dependen}

Variabel Dependen (Y) adalah variable terikat atau variable utama dari penelitian. $\mathrm{Va}$ riable dependen dalam penelitian ini adalah cash holdings. Menurut Gill \& Shah (2012), mendefinisikan cash holdings adalah kas yang dipegang oleh perusahaan sebagai uang tunai ditangan atau diinvestasikan pada aset lancar dan membagikannya kepada investor.

Menurut Gill dan Shah (2012), cash holding didefinisikan sebagai kas ditangan atau tersedia 
untuk diinvestasikan pada aset fisik dan untuk dibagikan kepada investor. Semakin tinggi tingkat cash holdings semakin tinggi jumlah kas yang tersedia.

Cash holdings dapat diukur menggunakan rasio dari kas dan setara kas dengan total aset (Ogundipeet al.,2012).

CH $=\frac{\text { Kas dan Setara Kas }}{\text { Total Asset }}$

\section{Variable Independen}

A. Net Working Capital (NWC)

Net working capital didefinisikan sebagai bagian dari aktiva lancar yang benar-benar dapat digunakan untuk membiayai operasional perusahaan tanpa mengganggu likuiditas perusahaan. Gill dan Shah (2012), mengukur besarnya net working capital yang dimiliki perusahaan menggunakan formula berikut:

$$
\text { NWC }=\frac{\text { Net Curren Assets- Kas \& Setara kas }}{\text { Total Aset }- \text { Kas \& setara kas }}
$$

\section{B. Interest Income Growth (ICG)}

Menurut Bartonet al. dalam Prasentianto (2014), Sales Growth merupakan manifestasi keberhasilan investasi periode masa lalu dan dapat dijadikan sebagai prediksi pertumbuhan di masa yang akan datang. Keown, et.al (2011) menggunakan formula tingkat sales growth sebagai berikut:

$$
\begin{gathered}
\text { ICIG }=\frac{\text { II1-IISo }}{-} \text { So } \\
\text { So } 100 \% \\
\hline
\end{gathered}
$$

Keterangan :

SG = Pertumbuhan Penjualan

II1 = total pendapatan bunga selama periode berjalan

Is0 = total pendapatan bunga periode yang lalu

\section{Capital Expenditure (CAPEX)}

Capital expenditure merupakan biaya-biaya yang dikeluarkan dalam rangka memperoleh aset tetap atau menambah manfaat ekonomis aset tetap yang dimiliki aset perusahaan. Penambahan manfaat ekonomis aset tetap tersebut antara lain dapat dilakukan melalui perpanjangan umur dan peningkatan produktivitas aset tetap. Capital expenditure mencakup beberapa kegiatan yaitu penambahan, perbaikan dan penggantian, serta pengaturan dan pemindahan aset tetap (Nikolay, Bazley, Jones dalam Ratnasari, 2015)

Rumus yang digunakan untuk menghitung capital expenditure mengikuti perhitungan yang dilakukan Bates et al, (2009),, Jinkar (2013), dan Ratnasari (2015) yaitu sebagai berikut :

$$
\text { CAPEX }=\frac{\text { Aset Tetap Aset Tetap }(t-1)}{\text { Total Aset }}
$$

\section{Aktivitas Dewan komisaris}

Kepemilikan institusional adalah kepemilikan saham perusahaan oleh institusi/badan. Diukur dengan prosentase (\%) kepemilikan saham oleh institusi. Dewan komisaris merupakan suatu mekanisme corporate governance berupa media dalam mengawasi dan memberikan petunjuk serta arahan pada manajemen.

Aktivitas Dewan Komisaris merupakan rapat yang diadakan oleh dewan komisaris berfungsi sebagai media komunikasi formal anggota dewan komisaris dalam mengawasi proses corporate governance; yang diukur dengan jumlah rapat dewan komisaris dalam satu tahun.

\section{Populasi dan Sampel Populasi}

Populasi dalam penelitian ini adalah perusahaan sektor jasa keuangan di Bursa Efek Indonesia pada periode 2012-2016.

\begin{tabular}{|c|l|c|}
\hline \multicolumn{3}{|c|}{ Tabel 3.2 Proses Pemilihan Sampel Periode 2012-2016 } \\
\hline No & \multicolumn{1}{|c|}{ Langkah Pengambilan Sampel } & $\begin{array}{c}\text { Total } \\
\text { Perusahaan }\end{array}$ \\
\hline 1 & $\begin{array}{l}\text { Total Perusahaan Jasa Keuangan yang listing di BEI } \\
\text { berdasarkan ICMD }\end{array}$ & 64 \\
\hline 2 & Dokumen Laporan Keuangan tidak lengkap & $(13)$ \\
\hline 3 & $\begin{array}{l}\text { Total Perusahaan yang dianggap memiliki } \\
\text { kelengkapan dokumen }\end{array}$ & 52 \\
\hline 4 & $\begin{array}{l}\text { Jumlah Perusahaan yang melakukan rapat Dewan } \\
\text { Komisaris kurng dari 4 kali }\end{array}$ & $(3)$ \\
\hline & Jumlah Sampel Penelitian ini & 48 \\
\hline
\end{tabular}

\section{HASIL dan PEMBAHASAN Hasil Penelitian Uji Statistik Deskriptif}

\begin{tabular}{|l|c|r|r|r|r|}
\hline \multicolumn{7}{|c|}{ Tabel 4.2. Deskriptif Statistik } \\
\hline & N & \multicolumn{1}{c|}{ Minimum } & \multicolumn{1}{c|}{ Maximum } & \multicolumn{1}{c|}{ Mean } & \multicolumn{1}{c|}{ Std. Deviation } \\
\hline IIG & 48 & -515279397.00 & 51605.00 & -35452530.7083 & 120769722.73076 \\
\hline NWC & 48 & -937900637.00 & 523455795.00 & -293889218.4167 & 366975196.60376 \\
\hline CAPEX & 48 & -409000044.00 & 3333686773.00 & 253550574.8333 & 581525393.43801 \\
\hline ADK & 48 & 4.00 & 8.00 & 5.4167 & 1.59565 \\
\hline CH & 48 & 73005.00 & 8856522597.00 & 224951997.8333 & 1274813650.47772 \\
\hline $\begin{array}{l}\text { Valid N } \\
\text { (listwise) }\end{array}$ & 48 & & & & \\
\hline & & & & \\
\hline
\end{tabular}

Statistik Deskriptif tentang variabel penelitian menggambarkan bahwa variabel IIG 
memiliki nilai minimum sebesar -515279397.00, nilai maksimum sebesar 51605.00; dengan ratarata -35452530,70 dengan standar deviasi sebesar 120769722,73. Standar deviasi IIG lebih besar dari rata-ratanya; hal ini menunjukkan bahwa data variabel IIG berfluktuasi. Variabel NWC memiliki nilai minimum sebesar -937900637,00, nilai maksimum sebesar 523455795,00, dengan rata-rata sebesar -293889218,41; dengan standar devisi sebesar 366975196,60. Standar deviasi NWC lebih besar dari rata-ratanya; hal ini menunjukkan bahwa data variabel NWC berfluktuasi. Variabel CAPEX memiliki nilai minimum sebesar $-409000044,00$, nilai maksimum sebesar 3333686773,00, dengan rata-rata sebesar 253550574,83 , dengan standar deviasi sebesar 581525393,44, Standar deviasi CAPEX lebih besar dari rata-ratanya; hal ini menunjukkan bahwa data variabel CAPEX berfluktuasi. Variabel ADK memiliki nilai minimum sebesar 4,00 , nilai maksimum sebesar 8,00; dengan rat-rata sebesar 5,4167; Nilai rata-rata lebih besar dari standar deviasi 1,59565; hal ini menunjukkan bahwa mekanisme kontrol yang dilakukan oleh Dewan Komisaris pada perusahaan sampel baik selama periode pengamatan.

Variabel $\mathrm{CH}$ memiliki nilai minimum sebesar 73005,00 , nilai maksimum sebesar 8856522597,00 ; dengan rat-rata sebesar 224951997,83; Nilai ratarata lebih besar dari standar dviasi 1274813650,48; hal ini menunjukkan bahwa mekanisme kontrol yang dilakukan oleh Dewan Komisaris pada perusahaan sampel baik selama periode pengamatan.

\section{Uji Hipotesis}

Pengujian hipotesis ini dimaksudkan untuk menjawab pertanyaan-pertanyaan penelitian yang dilakukan. Dalam pengujian hipotesis dengan menggunakan alat analisis Structural Equaton Modeling (SEM) dengan program WarpPLS 6.00 berikut ini disajikan pengujian hipotesis dari model penelitian ini.

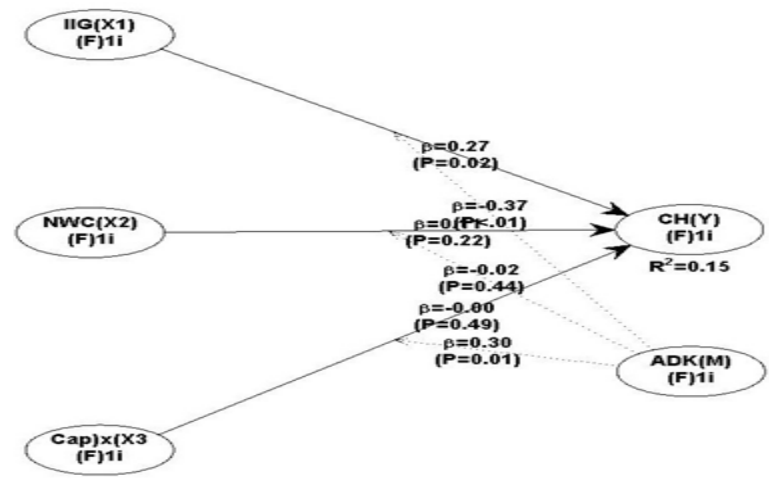

Gambar 4.1. Model Two Moderator hubungan IIG, NWC dan CAPEX terhadap Cash Holding
Gambar 4.1 di atas, menunjukkan perbedaan pengaruh perusahaan jasa keuangan antar variabel, dimana Interset Income Growth, Net Working Capital, Capital Expenditure, merupakan variabel independen dan Cash Holding sebagai variabel dependen dan dimoderasi oleh Aktivitas Dewan Komisaris.

Hasil Pengujian pengaruh Interest Income Growth (IIG) terhadap Cash Holding pada gambar 4.1 dapat dilihat pada koefisien jalur sebesar 0,27 p-value 0,02. Sedangkan hasil penelitian Aktivitas dewan komisaris (ADK) pada gambar 4.1 dapat dilihat koefisien jalur sebesar -0,37, dengan p-value $<0,01$.

Aktivitas Dewan komisaris (AKD) berpengaruh signifikan dan positif terhadap Cash Holding. Net Working Capital tidak berpengaruh terhadap Cash Holding, variabel Capital Expenditure tidak berpengaruh terhadap Cash Holding. Adapun hasil penelitian ini dapat dilihat pada tabel 4.3 berikut ini:

\begin{tabular}{|c|c|c|c|c|}
\hline \multicolumn{5}{|c|}{$\begin{array}{l}\text { Tabel 4.3. Hasil Path Coefficient dan } \\
\text { P-Value Perusahaan Jasa keuangan }\end{array}$} \\
\hline No & Hubungan Antar Variabel & Koefisien & P-Value & SE. \\
\hline 1 & $\| \mathrm{CH}$ & 0.27 & $0.02^{* * *}$ & 0,138 \\
\hline 2 & $\mathrm{NWC}=\mathrm{CH}$ & 0.11 & 0.22 & 0.144 \\
\hline 3 & CAPEX $=\mathrm{CH}$ & 0.00 & 0.49 & 0.130 \\
\hline 4 & $\| G^{*} A D K=C H$ & -0.37 & $<0.1^{* * *}$ & 0.129 \\
\hline 5 & $\mathrm{NWC}{ }^{*} \mathrm{ADK}=\mathrm{CH}$ & -0.02 & 0.44 & 0.143 \\
\hline 6 & CAPEX*ADK $=\mathrm{CH}$ & 0.30 & $0.01^{* * *}$ & 0.125 \\
\hline
\end{tabular}

Notasi:

$\mathrm{CH} \quad$ : Cash Holding

NWC : Net Working Capital

CAPEX : Capital Expenditure

ICG : Interest Income Growth

ADK : Aktivitas Dewan Komisaris

Pengujin Full Model dengan Two Moderator

Untuk dapat menjawab hipotesis penelitian maka harus dilakukan pembuatan SEM Model yang menggambarkan hubungan kausalitas dengan double moderasi antar variabel; mka setelah run-test diperoleh model sebagai berikut:

A. Pengaruh Interest Income Growth Terhadap Cash Holding

Pengujian hipotesis $\mathrm{H}_{1}$ menunjukkan bahwa pada persamaan model variabel Intererst Income Growth berpengaruh secara signifikan. Oleh karena itu pengujian terhadap persamaan model pertama menghasilkan kesimpulan yang konsisten dan signifikan terhadap dengan hipotesis satu $\left(\mathrm{H}_{1}\right.$ ditolak) yaitu Interest Income Growth berpengaruh positif signifikan terhadap Cash Holding. Hasil penelitian ini membuktikan 
bahwa Interest Income Growth dapat merubah Cash Holding, karena IIG hanya digunakan untuk biaya operasional jangka pendek dan kolektifitas pendanaan, dengan demikian terdapat hubungan antara IIG dengan Cash Holding. hasil penelitian ini searah dengan penelitian yang dilakukan oleh Bigelli dan Vidal (2009), yang menyatakan bahwa Terdapat hubungan positif dan signifikan antara variabel growth opportunity dengan Cash Holding.

\section{B. Pengaruh Net Working Capital Terhadap Cash Holding}

Pengaruh Net Working Capital (NWC) terhadap Cash Holding tidak berpengaruh, semakin tinggi Net Working Capital menunjukkan kecenderungan perusahaan mengalami kebangkrutan. Penelitian ini konsisten dengan penelitian Ur Rehman dan Wang (2015), bahwa perusahaan yang Net Working Capital negatif akan membuat cadangan kas. Sebaliknya jika perusahaan memiliki Net Working Capital yang besar otomatis akan mengurangi saldo kas mereka.

\section{Pengaruh Capital Expenditure Terhadap Cash Holding}

Hasil pengujian, (H.3); menunjukkan bahwa pengaruh Capital Expenditure terhadap Cash Holding tidak berpengaruh signifikan, Penelitian ini searah dengan penelitian Ur Rehman dan Wang (2015), akan tetapi bertentangan dengan penelitian Warsono (2016). Capital Expenditure yang tinggi berarti perusahaan melakukan pengeluaran untuk belanja modal, sehingga kas yang ada di perusahaan akan digunakan sebagian besar untuk belanja modal (memenuhi Capital Expenditure); dengan demikian semakin tinggi tingkat expenditure tidak mempengaruhi aktivitas manajemen dalam menahan kas (Cash Holding).

\section{Pengaruh Interest Income Growth Terhadap Cash Holding dengan Aktivitas Dewan Komisaris sebagai Pemoderasi}

Hasil penelitian menunjukkan bahwa hubungan antara Interest Income Growth terhadap Cash Holding yang dimoderasi oleh ADK berpengaruh signifikan. Dengan demikian ADK sebagai variabel pemoderasi baik hubungan antara IIG terhadap Cash Holding, Kontrol yang dilakukan oleh dewan komisaris sudah baik dilakukan, sehingga semakin sering dilakukan rapat Dewan Komisaris akan meningkatkan pengeluaran kas.; dengan demikian tingkat pertumbuhan lana (interest) terpengaruh oleh peran Aktivitas Dewan Komisaris dalam menahan kas (Cash Holding). Dengan kata lain bahwa Aktivitas Dewan Komisaris memperkuat hubungan antara IIG terhadap Cash Holding.

\section{E. Pengaruh Net Working Capital Terhadap Cash Holding dengan Aktivitas Dewan Komisaris sebagai Pemoderasi}

Hasil penelitian menunjukkan bahwa hubungan antara aktivitas Dewan Komisaris terhadap Cash Holding yang dimoderasi oleh ADK tidak signifikan. Dengan demikian ADK bukan sebagai variabel pemoderasi baik hubungan antara NWC terhadap Cash Holding, Kontrol yang dilakukan oleh dewan komisaris sudah baik dilakukan, sehingga semakin sering dilakukan rapat Dewan Komisaris akan meningkatkan pengeluaran kas.; dengan demikian tingkat likuiditas (NWC) tidak terpengaruh oleh peran Aktivitas Dewan Komisaris dalam menahan kas (Cash Holding). Dengan kata lain bahwa Aktivitas Dewan Komisaris tidak memperkuat hubungan antara NWC terhadap Cash Holding.

\section{F. Pengaruh Capital Expenditure Terhadap Cash Holding dengan Aktivitas Dewan Komisaris sebagai Pemoderasi}

Hasil penelitian menunjukkan bahwa hubungan antara aktivitas Dewan Komisaris terhadap Cash Holding yang dimoderasi oleh ADK berpengaruh signifikan. Dengan demikian ADK sebagai variabel pemoderasi hubungan antara CAPEX terhadap Cash Holding. Semakin meningkatnya Capital Expenditure diperkuat oleh Aktivitas Dewan Komisaris; hal ini menunjukkan bahwa peran kontrol dewan Komisaris berhubungan dengan belanja modal; karena belanja modal perusahaan dilakukan oleh kebijakan manajemen dalam pasar uang dan pasar modal; dengan demikian Aktivitas dewan Komisaris mendukung ketersediaan kas karena kegiatan belanja modal (Capital Expenditure), Dengan demikian dapat disimpulkan bahwa ADK memoderasi hubungan antara Capital Expenditure terhadap Cash Holding yang menyatakan bahwa terdapat hubungan antara Capital Expenditure diperkuat oleh Aktivitas dewan Komisaris.

\section{SIMPULAN}

\section{Kesimpulan}

Kesimpulan yang diperoleh dari hasil analisis pengaruh Net Working Capital, Capital Expenditure, dan Interest Income Growth dan Aktivitas Dewan Komisaris sebagai variabel Moderasi terhadap Cash Holdings adalah sebagai berikut:

1. Interest Income Growth berpengaruh positif terhadap Cash Holding, artinya semakin besar Interest Income Growth memberikan pengaruh peningkatan Cash Holding. Sebaliknya semakin kecil Interest Income Growth akan memberikan pengaruh menurunnya Cash Holding. Hasil penelitian ini searah 
dengan motif transaksi menahan kas, dimana keuntungan dari memegang kas adalah perusahaan dapat menurunkan biaya transaksi dengan menggunakan kas dari pada melikuidasi aset. Perusahaan akan memiliki lebih banyak kas ketika biaya transaksi tinggi untuk mengubah aset non-tunai untuk menjadi kas. Sementara itu, perusahaan akan memegang kas dalam jumlah yang lebih sedikit ketika biaya kesempatan dari kas menjadi lebih tinggi, terdapat kecenderungan perusahaan menggunakan kas mereka untuk membiayai peluang investasi yang lebih menguntungkan.

2. Net Working Capital berpengaruh positif dan signifikan terhadap Cash Holding, artinya semakin besar Net Working Capital memberikan pengaruh peningkatan Cash Holding. Sebaliknya semakin kecil Net Working Capital akan memberikan pengaruh menurunnya Cash Holding. Hasil penelitian ini searah dengan prespektif manajerial (Teori Keagenan), Motif memegang kas juga dipengaruhi oleh motif keagenan. Agen yang dimaksud di sini adalah para manajer selaku pihak yang mendapatkan wewenang dari pemegang saham untuk mengelola aset-aset perusahaan agar memberikan keuntungan bagi para pemegang saham.

3. Capital Expenditure berpengaruh positif terhadap Cash Holding, artinya semakin besar Capital Expenditure memberikan pengaruh peningkatan Cash Holding. Sebaliknya semakin kecil Capital Expenditure akan memberikan pengaruh menurunnya Cash Holding. Hasil penelitian ini searah dengan motif Cash Holding, motif berjagajaga, perusahaan memegang kas sebagai tindakan pencegahan untuk melindungi kekurangan kas di masa depan (Keynes dalam Keown et al,2011). Perusahaan memegang kas dalam jumlah yang banyak dengan tujuan agar bisa menghadapi terjadinya guncangan yang merugikan ketika akses masuk kepasar modal membutuhkan biaya yang mahal. Dengan demikian, perusahaan dengan peluang investasi yang lebih baik akan memegang kas dalam jumlah yang lebih besar sehingga tetap bisa membiayai kebutuhan investasinya sekalipun guncangan perekonomian dan financial distress sedang melanda.

4. Aktivitas Dewan Komisaris berpengaruh positif signifikan terhadap Cash Holding, artinya semakin besar Aktivitas Dewan Komisaris memberikan pengaruh peningkatan Cash Holding. Sebaliknya semakin ke cil Aktivitas Dewan Komisaris akan mem- berikan pengaruh menurunnya Cash Holding. Hasil ini memperkuat asumsi bahwa Aktivitas Dewan Komisaris dapat digunakan sebagai alat monitoring manajemen dalam mengontrol besarnya ekses Cash Holding.

\section{Keterbatasan}

Penelitian ini dilakukan pada perusahaan jasa keuangan yang terdaftar di Bursa Efek Indonesia, dengan keterbatasan antar lain :

1. Pengambilan sampel secara keseluruhan dapat berakibat heteroskedakstisits tinggi, karena semua emiten jasa keuangan mempunyai kebutuhan menahan kas atau Cash Holding. Kelemahan ini dapat diatasi dengan menambahkan kriteria sampel dengan emiten yang masuk ke dalam kelompok kas yang besar.

2. Pengukuran Aktifitas Dewan Komisaris memiliki subyektifitas yang tinggi karena penentuan Atifitas Dewan Komisaris hanya dilakukan dengan justifikasi peneliti dan tidak meminta pendapat pihak yang memahami atau yang memiliki kompetensi; Hal tersebut berdampak pada jenis data yang disajikan.

\section{Implikasi Penelitian}

Berdasarkan hasil pengujian yang telah dilakukan pada bab-bab terdahulu, maka penelitian ini dapat memberikan kontribusi sebagai berikut.:

\section{Implikasi Teoritis}

1. Hasil penelitin ini menunjukkan bahwa Net Working Capital, Capital Expenditure, Interest Income Growth dan Aktifitas Dewan Momisaris pada perusahaan jasa keuangan yang terdaftar di BEI berpengaruh signifikan terhadap Cash Holding. Hal ini sesuai dengan teori agensi bahwa manajer yang terlatih mencoba untuk memegang kembali kas yang dimiliki perusahaan dari pada harus membayarkannya kepada pemegang saham ketika perusahaan memiliki peluang investasi yang kecil. Alih-alih meningkatkan kesejahteraan pemegang saham, manajermanajer tersebut cenderung menggunakan kas yang menganggur tersebut untuk mendapatkan keuntungan bagi diri mereka sendiri.

2. Pengaruh Capital Expenditure, Interest Income Growth berpengaruh positif terhadap Cash Holding, hal ini mengungkapkan motif perusahaan dalam memegang kas sebagai motif transaksi dan motif berjaga-jaga, biaya transaksi dengan menggunakan kas dari pada melikuidasi aset. Perusahaan akan memiliki lebih banyak kas ketika biaya transaksi tinggi untuk mengubah aset non-tunai untuk men- 
jadi kas. Sementara itu, perusahaan akan memegang kas dalam jumlah yang lebih sedikit ketika biaya kesempatan dari kas menjadi lebih tinggi, terdapat kecenderungan perusahaan menggunakan kas mereka untuk membiayai peluang investasi yang lebih menguntungkan.

Berdasarkan motif berjaga-jaga, perusahaan memegang kas sebagai tindakan pencegahan untuk melindungi kekurangan kas di masa depan. Perusahaan memegang kas dalam jumlah yang banyak dengan tujuan agar bisa menghadapi terjadinya guncangan yang merugikan ketika akses masuk kepasar modal membutuhkan biaya yang mahal. Dengan demikian, perusahaan dengan peluang investasi yang lebih baik akan memegang kas dalam jumlah yang lebih besar sehingga tetap bisa membiayai kebutuhan investasinya.

\section{Implikasi Kebijakan}

Hasil penelitian ini memberikan kontribusi kepada pihak manajemen, investor maupun calon investor dan pihak pemerintah.

\section{Implikasi Kebijakan bagi Perusahaan}

Implikasi bgi perusahaan jasa keuangan, Variabel Net Working Capital, Capital Expenditure dan Interest Income Growth memitigasi perilaku opportunistik manajemen dalam mengontrol Exces Cash Holding Perusahaan.

\section{Implikasi Kebijakan bagi Investor}

Hasil Penelitian ini menunjukkan bahhwa aktifitas Cash Holding akan mempengaruhi laba perusahaan, karena Cash Holding yang tinggi mengakibatkan rendahnya likuiditas perusahaan, hal ini akan direspon negatif oleh pasar berakibat menurunnya earning per share saham perusahaan tersebut.

\section{Implikasi Kebijakan bagi Pemerintah}

Hasil Penelitian ini menunjukkan bahhwa aktifitas Cash Holding berkenaan dengan biaya yang harus dikeluarkan perusahaan, misalnya bank BUMN yang melakukan Cash Holding yang tinggi akan mengkibatkan pemborosan. Oleh karena itu Kementerian BUMN menerbitkan peraturan tentang pengadaan barang dan jasa PERATURAN PRESIDEN REPUBLIK INDONESIA NOMOR 70 TAHUN 2012 TENTANG PERUBAHAN KEDUA ATAS PERATURAN PRESIDEN NOMOR 54 TAHUN 2010 TENTANG PENGADAAN BARANG/JASA PEMERINTAH. Perusahaan dapat melakukan Cash Holding sesuai dengan perencanaan perencanaan kebutuhan sampai diselesaikannya seluruh kegiatan untuk memperoleh Barang/Jasa.

\section{DAFTAR PUSTAKA}

Agus Harjito dan Martono, Manajemen Keuangan. Edisi Kedua, Cetakan Pertama, Penerbit EKONISIA, Yogyakarta, 2011. Adrian, Sutedi. 2011. Good Corporate Governance. Jakarta : Sinar Grafika

Anjum, S. and Malik, Qaisar A. 2013. Determinants of Corporate Liquidity-An Analysis of Cash Holdings. Journal of Business and Management. Vol 7, Issue 2, PP 94-100

Basheer, M Farhan. 2014. Impact of Corporate Governance on Corporate Cash Holdings : An Empirical Study of Firms in Manufacturing Industry of Pakistan. International Journal of Innovation and Applied Studies. Vol 7 No.4 ,pp. 1371-1383.

Bates, T., Kahle, K., Stulz, R. 2009. Why Do US Firms Hold So Much Cash Than They Used To $B e$ ?. Journal of Finance, 64, 1985-2021.

Baumol, W. J. (1952). The Transactions Demand for Cash: An Inventory Theoretic Approach. Quarterly Journal of Economics, 66, 545-556.

Brigham, E. F dan Houston, J.F. 2011. Dasar-dasar Manajemen Keuangan. Diterjemahkan oleh: Ali Akbar Yulianto, Buku 2, Edisi 11, Salemba Empat, Jakarta.

Christina, Yessica, dan Ekawati, Erni.2014. Excess Cash Holdings dan Kepemilikan Institusional pada Perusahaan Manufaktur yang Terdaftar di BEI. Jurnal Universitas Kristen Duta Wacana, Yogyakarta-Indonesia.

Daher, M. (2010). The Determinants of Cash Holdings in UK Public and Private Firms. United Kingdom: Dissertation. Lancaster University Management School,

Edward Lee dan Powell, Daher, Ronan. 2010. Excess Cash Holdings and Shareholder Value. (Online), (http://papers.ssrn.com/sol3/ papers.cfm?abstract_id=1585623, diakses 19 Januari 2018)

Ferreira, M.A., \& Vilela, A.S. 2004. Why do firms hold cash? Evidence from EMU countries. European Financial Management, 10(2), 295-319

Gill, A. and Shah,C.2012. Determinants of Corporate Cash Holdings: Evidence from Canada. International Journal of Economics and Finance. Vol. 4, No. 1; January 2012.

Halim, Abdul. 2015. Manajemen Keuangan Bisnis: Konsep dan Aplikasinya. Edisi pertama. Jakarta: Mitra Wacana Media

Hanafi, Mamduh M. 2016. Manajemen Keuangan (Edisi 2). Cetakan Pertama. Yogyakarta: BBPE.

Harmono, 2015. Manajemen Keuangan. (R. Rachmatika, Ed.) Jakarta: Bumi Askara.

Harford, J., S.A. Mansi, dan W.F. Maxwell. (2008). Corporate governance and cash holdings. 
Journal of Financial Economics, Vol. 87 No. 3, pp. 535-55.

Hendrawaty, Ernie. 2014. Peran Corporate Governance dalam Mengendalikan Masalah Keagenan yang Ditimbulkan Oleh Excess Cash Holdings. Theses and Dissertations. Universitas Gadjah Mada.

Husnan, Suad. 2015. Dasar-Dasar Teori Portofolio dan Analisis Sekuritas. Edisi kelima. BPFE. Yogyakarta.

Husnan, Suad.2013. Manajemen Keuangan Lanjutan (Teori dan Penerapan Keputusan Jangka Pendek), Edisi Revisi. BPFE. Yogyakarta.

Ikatan Akuntansi Indonesia, 2012. Standar Akuntansi Keuangan. PSAK. Cetakan Keempat, Buku Satu, Jakarta: Penerbit Salemba Empat, Jakarta.

Islam, S.2012. Manufacturing Firms' Cash Holding Determinants: Evidence from Bangladesh. International Journal of Business and Management. Vol. 7, No. 6; March 2012

Jensen \& Meckling,1976, The Theory of The Firm : Manajerial Behavior, Agency Cost, and Ownership Structure, Jurnal of financial and Ecomonics, 3:305-360

Jinkar, Rebecca T. 2013. Analisa Faktor-Faktor Penentu Kebijakan Cash Holding Perusahaan Manufaktur di Indonesia. Jurnal Departemen Akuntansi. Universitas Indonesia

Jogiyanto. 2013. Teori Portopolio dan Analisis Investasi, Yogyakarta BPFE: Edisi Delapan.

Kasmir. 2015. Analisis Laporan Keuangan. Jakarta : PT Raja Grafindo Persada.

Keown, Arthur J, et al. 2011. Manajemen Keuangan: Prinsip dan Penerapan. Edisi Kesepuluh Jilid I, Indeks, Jakarta.

Kusnadi, Y. 2003. Corporate Cash Holding, Board Structure, and Ownership Concentration: Evidence From Singapure. Hong Kong University of Science and Technology

Magerakis, E. 2015. Cash Holding and Firm Characteristics : Evidence From UK Market. Master Thesis. University of Patras.

Masood, A., dan Shah, A., (2014). "Corporate Governance and Cash Holdings in Listed Non-Financial Firms of Pakistan". Business Review. 9(2). Pp 48- 72

Miller, M. H., \& Orr, D. (1966). A Model of the Demand for Money by Firms. The Quarterly Journal of Economics, Vol. 80, No. 3, 413435.

Muh. Arief, Effendi. 2009. The Power of Good Corporate Governance : Teori dan Implementasi. Jakarta : Salemba Empat

Ogundipe, L. Olatunde, Sunday E. Ogundipe, Samuel K. Ajao. 2012. Cash Holding and Firm Characterictics : Evidence From Nigerian Emerging Market, Journal of Business, Eco- nomic \& Finance, Volume: 1, Department of Business Education, Osun State College of Education, Nigeria.

Otoritas Jasa Keuangan. 2014. Peraturan Otoritas Jasa Keuangan Nomor 33/PJOK 04/2014 Tentang Direksi dan Dewan Komisaris Emiten atau Perusahaan Publik. Jakarta Otoritas Jasa Keuangan.

Pastor, C. 2010. Why Do SMEs Hold Cash? Evidence From Portugal. Journal University of Coimbra, Portugal.

Prasentianto, Hanafi. 2014. Analisis Faktor-Faktor yang Mempengaruhi Tingkat Cash Holding (Studi Empiris pada Perusahaan Property dan Real Estate yang Terdaftar di Bursa Efek Indonesia Tahun 2009-2013).

Rahmawati, Zahrotun A.2013 . Faktor-Faktor yang Memengaruhi Keputusan Cash Holding pada Perusahaan Food and Beverages yang Terdaftar di Bursa Efek Indonesia (BEI). Jurnal Universitas Brawijaya.

Ranjan D'Mello, Sudha Krishnaswami, dan Patrick J. Larkin An Analysis of the Corporate Cash Holding Decision (2005)

Retno Prasetyorini. 2003. Pelayanan Prima. Penerbit, Liberty. Yogyakarta.

Sartono, Agus. 2012. Manajemen Keuangan: Teori Praktik. Edisi Keempat. Cetakan keenam. Yogyakarta: BPPE. Yogyakarta.

Subramanyan, K. R, John J. Wild. 2012. Analisis Laporan Keuangan. Edisi 10. (Penerjemah: Dewi Yanti). Jakarta: Salemba Empat.

Suherman (2017), Faktor-faktor yang mempengaruhi Cash Holdings perusahaan di bursa Efek Indonesia

Sutrisno. 2012. Manajemen Keuangan Teori. Konsep dan aplikasi ( $\left.8^{\text {th }} e d\right)$. Yogyakarta: Ekonisia.

Syafrizaliyadhi, Aditya D. 2014. Faktor-Faktor yang Memengaruhi Perilaku Cash Holding pada Perusahaan Besar dan Perusahaan Kecil

Syakur, Ahmad Syafi'I. 2015. Intermediate Accounting. Jakarta: AV Publisher

Sutedi, Adrian, 2011, Good Corporate Governance, Jakarta : Sinar Grafika

ur Rehman, A., dan Wang, M., (2015). "Corporate Cash Holdings and adjustment behaviour in Chinese firms: An empirical analysis using generalized method of moments". Australasian Accounting Business \& Finance Journal. 9(4). Pp 20-37

Warsono,2016 Capital Expenditure Memoderasi Kepemilikan Institusonal terhadap Exses holdings di Indonesia, Proceeding Konggres Ilmiah Akuntnsi (KIA) IV, halaman 25-28.

Wasiuzzaman, S. (2014), Analysis of corporate cash holdings of firms in Malaysia. Journal of Asia Business Studies, 8 (2), 118-135.

Zulhilmi, Marfuah A. 2014. Pengaruh Growth 
Opportunity, Net Working Capital, Cash Conversion Cycle and LeverageTerhadap Cash Holding Perusahaan. Jurnal Universitas Islam Indonesia.

http//www.idx.co.id

http//www.ojk.go.id 